in vivo $32: 1373-1379(2018)$

doi:10.21873/invivo.11389

\title{
Banana Flower Extract Suppresses Benign Prostatic Hyperplasia by Regulating the Inflammatory Response and Inducing $G_{1}$ Cell-cycle Arrest
}

\author{
LIANG-CHIH LIU ${ }^{1,2}$, YUNG-HSIANG LIN ${ }^{3}$, YING-CHAO LIN ${ }^{4,5,6}$, CHI-TANG HO ${ }^{7}$, \\ CHAO-MING HUNG ${ }^{8,9}$, TZONG-DER WAY ${ }^{10}$ and DA-TIAN BAU ${ }^{11,12}$ \\ ${ }^{1}$ Department of Surgery, and ${ }^{12}$ Terry Fox Cancer Research Laboratory, \\ Translational Medicine Research Center, China Medical University Hospital, Taichung, Taiwan, R.O.C.; \\ ${ }^{2}$ Department of Medicine, College of Medicine, China Medical University, Taichung, Taiwan, R.O.C.; \\ ${ }^{3}$ TCI Co., Ltd. Taipei, Taiwan, R.O.C.; \\ ${ }^{4}$ Division of Neurosurgery, Buddhist Tzu Chi General Hospital, Taichung Branch, Taiwan, R.O.C.; \\ ${ }^{5}$ School of Medicine, Tzu Chi University, Hualien, Taiwan, R.O.C.; \\ ${ }^{6}$ Department of Medical Imaging and Radiological Science, \\ Central Taiwan University of Science and Technology, Taichung, Taiwan, R.O.C.; \\ ${ }^{7}$ Department of Food Science, Rutgers University, New Brunswick, NJ, U.S.A.; \\ ${ }^{8}$ Department of General Surgery, E-Da Hospital, I-Shou University, Kaohsiung, Taiwan, R.O.C.; \\ ${ }^{9}$ School of Medicine, I-Shou University, Kaohsiung, Taiwan, R.O.C.; \\ ${ }^{10}$ Department of Biological Science and Technology, College of Biopharmaceutical and Food Sciences, \\ China Medical University, Taichung, Taiwan, R.O.C.; \\ ${ }^{11}$ Department of Bioinformatics and Medical Engineering, Asia University, Taichung, Taiwan, R.O.C.
}

\begin{abstract}
Background/Aim: The banana flower is used for ameliorating urinary disturbance. However, there is limited evidence to support the efficacy or mechanism of action of banana flower against benign prostatic hyperplasia (BPH). In the present study, the anti-BPH activity and mechanisms of banana flower extracts were investigated in vitro and in vivo. Materials and Methods: The banana flower extract is a watersoluble extract obtained by sonication. MTT assay was used to examine whether banana flower extract exhibited cytotoxic
\end{abstract}

This article is freely accessible online.

Correspondence to: Da-Tian Bau, Ph.D., Terry Fox Cancer Research Laboratory, Translational Medicine Research Center, China Medical University Hospital, 2 Yuh-Der Road, Taichung, 404 Taiwan, R.O.C. Tel: +886 422053366 Ext. 5805, e-mail: datian@ mail.cmuh.org.tw; artbau2@gmail.com and Tzong-Der Way, Ph.D., Department of Biological Science and Technology, College of Biopharmaceutical and Food Sciences, China Medical University, Taichung, Taiwan No.91 Hsueh-Shih Road, Taichung, Taiwan 40402, R.O.C. Tel: +886 422053366 ext: 2509, Fax: +886 422031075, e-mail: tdway@mail.cmu.edu.tw

Key Words: Banana flower extract, Benign prostatic hyperplasia, $\mathrm{G}_{0} / \mathrm{G}_{1}$ arrest, cyclooxygenase-2, prostaglandin $\mathrm{E}_{2}$. effects on BPH-1 cells. The effect of banana flower extract on cell-cycle distribution was examined by flow cytometry. The expression of cell-cycle-regulatory molecules was determined by western blot analysis. Testosterone propionate (TP)induced rat model of $B P H$ was used to evaluate the anti-BPH activity of banana flower extract in vivo. Results: Banana flower extract reduced epithelial cell line BPH-1 cell viability through cell-cycle arrest at $G_{1}$ phase. Moreover, banana flower extract reduced the expression of cyclin D1 and cyclindependent kinase 6, while it increased the expression of p53 and $\mathrm{p} 27$. Interestingly, banana flower extract suppressed $\mathrm{BPH}$ related inflammatory responses through suppressing cyclooxygenase-2 expression and prostaglandin E2 production. Finally, banana flower extract administered orally to male rats reduced prostatic weight and serum dihydrotestosterone level, and improved prostate gland morphology. Highperformance liquid chromatography revealed that banana flower extract contains citric acid, taurine, pantothenic acid and nicotinic acid components. In summary, banana flower extract may be used as a therapeutic agent for BPH via antiproliferative and anti-inflammatory activities.

Benign prostatic hyperplasia (BPH), an enlarged prostate gland, is the most common urological disease affecting about $50 \%$ of men aged over 50 years (1-3). Moreover, more than half of 
these patients will go on to develop a macroscopic nodular enlargement that gradually results in lower urinary tract symptoms (LUTS) $(4,5)$. LUTS encompasses all urinary symptoms, namely, voiding (frequency, urgency and nocturia), urinary storage (hesitancy, weak streaming and retention), or postvoiding. Due to hormonal imbalances in aging men, the prevalence and incidence of LUTS secondary to BPH has steadily increased (6). The effects of estrogen/androgen balance, and inflammation-mediated oxidative stress in the prostate gland affect the progression of BPH (7).

$5 \alpha$-Reductase $(5 \alpha \mathrm{R})$ inhibitors, which inhibit the conversion of testosterone to dihydrotestosterone (DHT), are used for the treatment of symptomatic BPH. As a result of side-effects such as headache, nasal congestion, sexual dysfunction, diarrhea, and orthostatic hypotension, the application of $5 \alpha \mathrm{R}$ inhibitors are very limited $(8,9)$. Therefore, it is necessary to development new drugs that can alleviate the development of BPH. Recently, dietary interventions derived from natural substances have been identified for their potential in the management of BPH.

Banana (Musa acuminata), a main economy crop in Taiwan, is rich in vitamins and minerals, such as vitamin $C$, magnesium and potassium. Over the past few decades, increasing attention has focused on the health benefits of $M$. acuminata. All parts of banana have many traditional and documented medicinal uses and have been used to treat many diseases $(10,11)$. The banana flower exhibits high nutritional value like the banana fruit. Tribal communities have used banana flower as an important wild food and medicinal plant $(10,11)$. Much remains to be studied about banana flower, especially banana stamens.

The role of banana flower for treatment of $\mathrm{BPH}$ is not fully defined. In the present study, we investigated the antiBPH efficacy of a water extract of banana flowers and its mechanisms.

\section{Materials and Methods}

Chemicals and reagents. 3-[4,5-Dimethylthiazol-2-yl]-2,5-diphenyltetrazolium (MTT) and propidium iodide (PI) were purchased from Sigma Chemical Co. (St. Louis, MO, USA). Cyclin D1 and cyclindependent kinase 6 (CDK6) antibodies were purchased from St John's Laboratory Ltd. (London, UK). p53, p27, cyclo-oxygenase-2 (COX2) and $\beta$-actin antibodies were purchased from Cell Signaling Technology (Beverly, MA, USA). Secondary antibodies were purchased from Life Technologies Co. (Carlsbad, CA, USA).

Cell lines and cell culture. BPH epithelial cell line BPH-1 was obtained from the American Type Culture Collection (Rockville, MD, USA) and maintained in RPMI 1640 medium (Gibco, Grand Island, NY, USA) supplemented with $10 \%$ fetal bovine serum (FBS) (Invitrogen, Carlsbad, CA, USA), $1 \%$ L-glutamine, penicillin $(50 \mathrm{U} / \mathrm{ml})$ (Invitrogen), at $37^{\circ} \mathrm{C}$ under an atmosphere of $5 \% \mathrm{CO}_{2}$ in air.

Preparation of banana flower extract. The banana flowers used in the present study included but were not limited to the flowers of

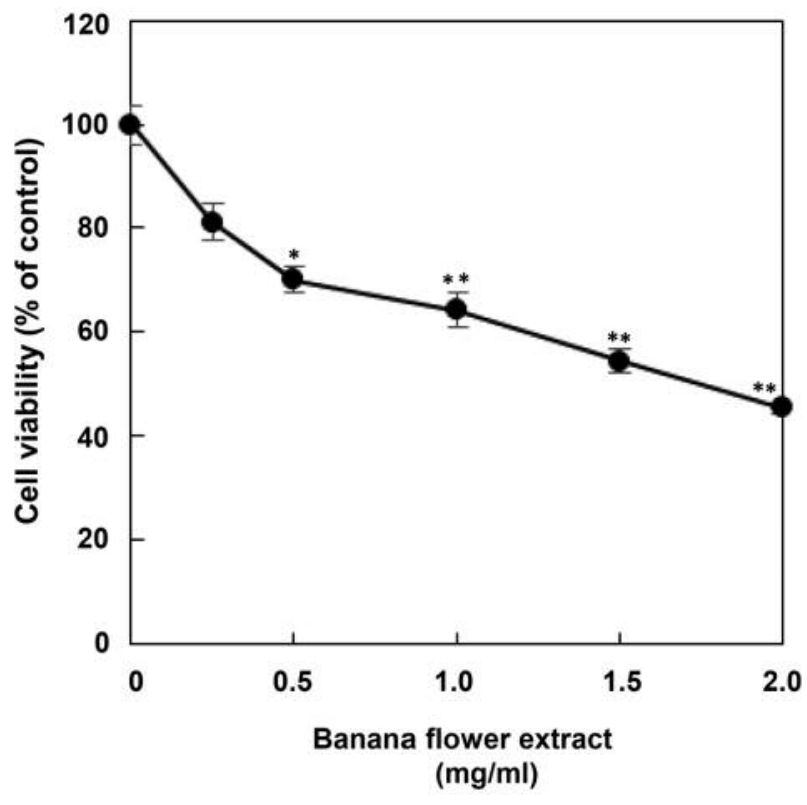

Figure 1. Effect of banana flower extract on the growth of BPH-1 cells. BPH-1 cells were treated with vehicle, or banana flower extract for $48 \mathrm{~h}$ at the indicated concentration and the relative cell viability was assessed using the 3-[4,5-dimethylthiazol-2yl]-2,5-diphenyl-tetrazolium bromide assay. The data are the mean \pm SEM of three independent experiments. Significantly different at $* p<0.05$, and $* * p<0.01$, compared with vehicle control.

Musa paradisiacal, Musa sapientum L., Musa spp. AAB Silk, Musa spp. ABB Bluggoe, Musa spp. AAA Robusta, Musa spp. AAB Bluggoe. Firstly, the stamens of banana flowers were harvested by hand or machine, and cleaned with water. The stamens of banana flowers were mixed with water at a ratio between $1: 4$ and 1:6, and extracted with cold-sonication for 0.5 to $2.0 \mathrm{~h}$ to obtain a crude banana flower extract. Finally, the crude banana flower extract was centrifuged and filtered through a 300-mesh screen (Heibei Accurux Wire Works, Anping, Hebei, China) to obtain banana flower extract.

Cell viability assay. Cell viability measurement was performed using MTT reagent (12). BPH-1 cells $\left(1 \times 10^{4}\right)$ were cultured in a 96-well plate, and treated with water (as control) and a series of concentrations of banana flower extract $(0.25,0.5,1.0,1.5,2.0 \mathrm{mg} / \mathrm{ml})$ for $48 \mathrm{~h}$. After treatment, MTT in phosphate-buffered saline (PBS) was added to each well at a final concentration of $500 \mu \mathrm{g} / \mathrm{ml}$. After $1 \mathrm{~h}$ of incubation, the solution was removed from each well and $80 \mu \mathrm{l}$ dimethyl sulfoxide was added to dissolve the crystals formed. The absorbance value was measured at $570 \mathrm{~nm}$ with an enzyme-linked immunosorbent assay (ELISA) reader (Bio-Rad, Hercules, CA, USA).

Western blotting analysis. According to a previous publication (13), protein concentration was determined by Bio-Rad Protein Assay (Bio-Rad, Hercules, CA, USA). Proteins $(50 \mu \mathrm{g})$ from the BPH-1 cells were separated using sodium dodecyl sulfatepolyacrylamide gel electrophoresis and transferred to polyvinylidene difluoride membrane. Membranes were then 
A

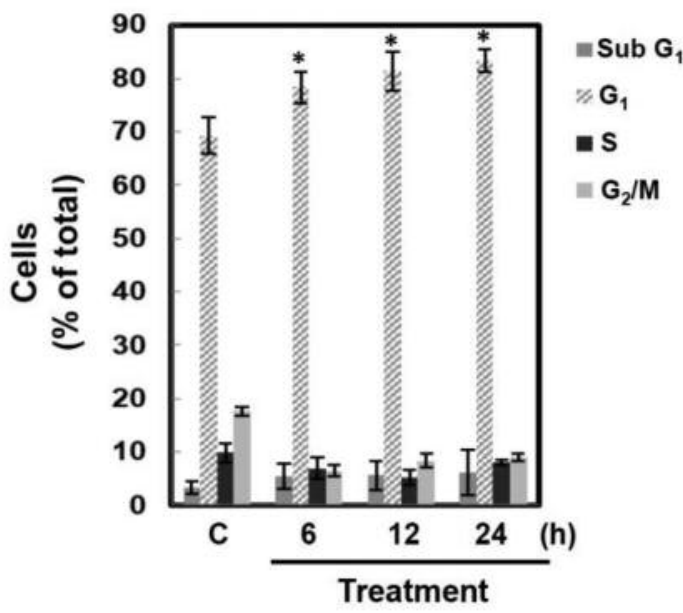

B

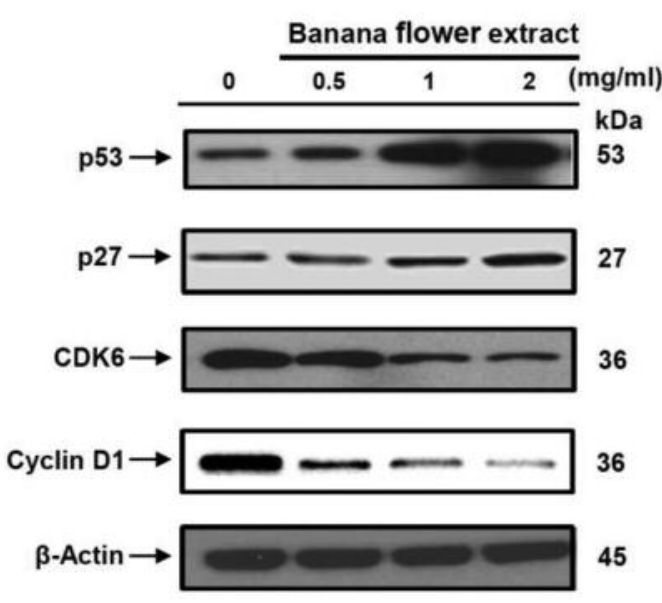

C

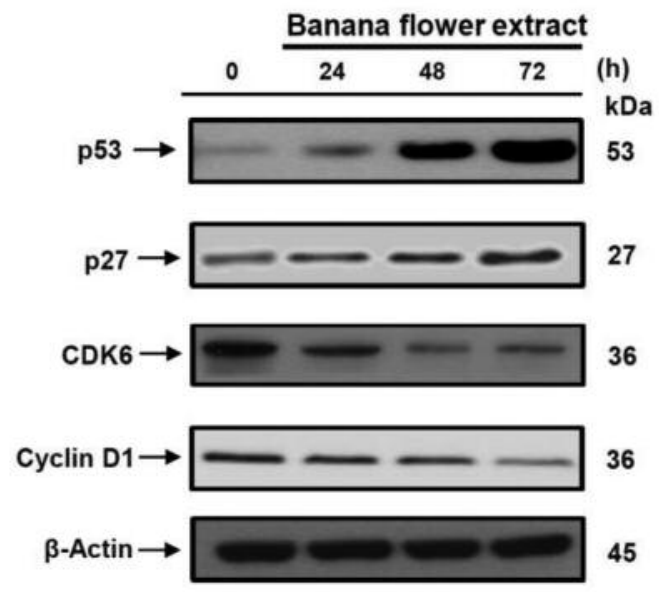

Figure 2. Effect of banana flower extract on cell-cycle distribution and expression of related proteins. A: BPH-1 cells were treated with banana flower extract $(2 \mathrm{mg} / \mathrm{ml})$ for the indicated time. The numbers of cells in different phases were determined by flow cytometry. The data are the mean $\pm S E M$ of three independent experiments. BPH-1 cells treated with banana flower extract at $0.5,1.0$ and $2.0 \mathrm{mg} / \mathrm{ml}$ for $48 \mathrm{~h}$. C. BPH-1 cells were treated with banana flower extract $(2 \mathrm{mg} / \mathrm{ml})$ for the indicated times. The levels of cyclin D1, cyclin-dependent kinase 6 (CDK6), p53, and p27 were determined by western blot analysis of whole-cell lysates. Western blot data are representative of at least three independent experiments. *Significantly different at $p<0.05$, compared with vehicle control.

probed with the following antibodies: anti-p53, anti-p27, antiCDK6, anti-cyclin D1, anti-COX2 and anti- $\beta$-actin. The immunoreactive bands were revealed using $\mathrm{ECL}^{\mathrm{TM}}$ Prime Western Blotting Detection Reagent (GE Healthcare UK Ltd.) and the results were quantitated by Image $\mathbf{J}$ software.

Flow cytometric analysis. BPH-1 cells $\left(1 \times 10^{4}\right)$ were collected by centrifugation, and the cell number was adjusted to a density of $\sim 1 \times 10^{6}$ cells $/ \mathrm{ml}$. Cells were then incubated with PI using flow cytometric kits (Abcam) according to the manufacturer's instructions. Finally, cell-cycle analysis was carried out by BD FACScan $^{\mathrm{TM}}$ system (BD Biosciences, San Jose, CA, USA).
Measurement of prostaglandin $E_{2}\left(P G E_{2}\right)$ release. $\mathrm{BPH}-1$ cells were seeded into 48 -well plates at $1 \times 10^{4}$ cells/well. Overnight, the medium was refreshed and a series of concentrations of banana flower extract were added to the medium for $24 \mathrm{~h}$. According to the manufacturer's instructions, culture supernatants were analyzed using $\mathrm{PGE}_{2}$ Enzyme Immunoassay Kit (Cayman Chem., Ann Arbor, MI, USA).

In vivo study. The animal study was approved by the Institutional Animal Care and Use Committee of China Medical University (\#105365). Moreover, the animal procedures were performed according to the Guide for the Care and Use of Laboratory Animals 


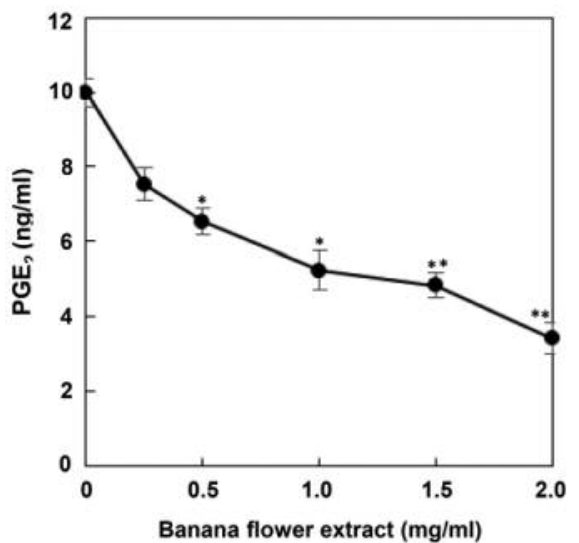

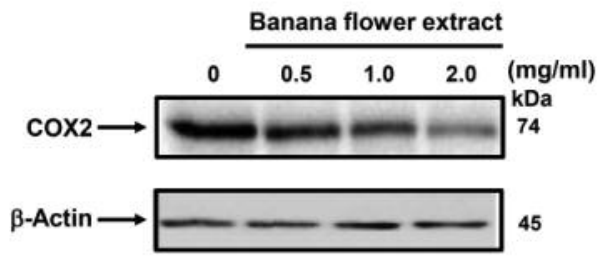

Figure 3. Effect of banana flower extract on inflammation in BPH-1 cells. A: BPH-1 cells were treated with vehicle, or banana flower extract for $24 \mathrm{~h}$ at the indicated concentration. Culture supernatants were analyzed for secreted prostaglandin E2 (PGE2). The data are the mean $\pm S E M$ of three independent experiments. Significantly different at ${ }^{*} p<0.05$, and $* * p<0.01$, compared to vehicle control. B: BPH-1 cells were treated with vehicle, or banana flower extract at 0.5, 1.0 and $2.0 \mathrm{mg} / \mathrm{ml}$ for $48 \mathrm{~h}$. The level of cyclo-oxygenase-2 (COX2) was determined by western blot analysis of whole-cell lysates. Western blot data are representative of at least three independent experiments.

(14). Seven-week-old male Sprague Dawley rats (200-220 g) were purchased from The BioLasco Taiwan Co., Ltd. (Taipei, Taiwan). Rats were randomized and divided into four groups (five mice/group). The negative control (NC) group was injected s.c. with $100 \mu \mathrm{l}$ corn oil and given $0.5 \mathrm{ml}$ PBS p.o.; a BPH control group was injected s.c. with $10 \mathrm{mg} / \mathrm{kg}$ of testosterone propionate (TP) (Sigma Chemical Co., St. Louis, MO, USA) dissolved in corn oil and given $0.5 \mathrm{ml}$ PBS p.o.; banana flower extract-treated groups were injected s.c. with $10 \mathrm{mg} / \mathrm{kg}$ of TP (Sigma Chemical Co.) and given either 200 or $500 \mathrm{mg} / \mathrm{kg}$ of banana flower extract p.o. All treatments were given 5 days a week for 4 weeks.

Measurement of DHT levels. After the animal study, the level of DHT in serum was determined using an ELISA kit according to the manufacturer's instructions (ALPCO Diagnostics, Salem, NH, USA) (15).

High-performance liquid chromatography (HPLC) analysis of the bioactive fraction. The HPLC separation was performed using WATERS HPLC system with 2487 dual $\lambda$ U-V detector. The sample and mobile phase were filtered through $0.22 \mu \mathrm{m}$ polyvinylidene difluoride filter before injecting to the column.

Statistical analysis. All values are presented as the mean \pm standard error of the mean (S.E.M) and were derived from at least three separate experiments for each group. Statistical analyses of data were performed with one-way analysis of variance with Dunnett's test Differences from the control were considered significant at $p<0.05$.

\section{Results}

Banana flower extract reduced epithelial cell line BPH-1 cell viability in vitro. BPH is usually described as a pathological proliferation of epithelial cells. In order to evaluate the antiproliferative activities of banana flower extract on $\mathrm{BPH}$, the epithelial cell line BPH-1 was treated with different concentrations of banana flower extract for $48 \mathrm{~h}$. Our study found that banana flower extract significantly inhibited cell viability in a dose-dependent manner (Figure 1). The data showed that banana flower extract exhibited efficient cytotoxic effects on BPH-1 cells.

Banana flower extract induced cell-cycle arrest at G1 phase in BPH-1 cells. We next assumed that banana flower extract affects cell-cycle regulation in BPH-1 cells. To explore this hypothesis, the populations of BPH-1 cells in different cellcycle stages were analyzed by flow cytometry. Treatment with $2 \mathrm{mg} / \mathrm{ml}$ of banana flower extract significantly induced cell-cycle arrest at G1 phase in BPH-1 cells (Figure 2A). To elucidate the arrest point of banana flower extract-treated BPH-1 cells in the G1 phase, the expression of cyclin D1, CDK6, p53 and CDK inhibitor p27 was determined by western blot analysis. Banana flower extract reduced the expression of cyclin D1 and CDK6, while it increased the expression of p53 and p27 in a dose- (Figure 2B) and timedependent manner (Figure 2C).

Banana flower extract suppressed BPH-related inflammatory responses in vitro. Inflammation plays a crucial role in the $\mathrm{BPH}$ growth and proliferation. To test whether banana flower extract inhibited inflammatory responses, we examined the production of $\mathrm{PGE}_{2}$, which is a potent inflammatory mediator. Banana flower extract significantly suppressed $\mathrm{PGE}_{2}$ production a dose-dependent manner (Figure 3A). 


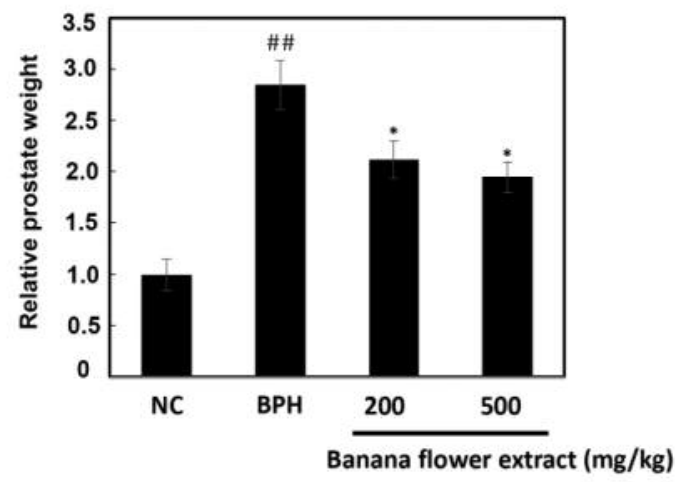

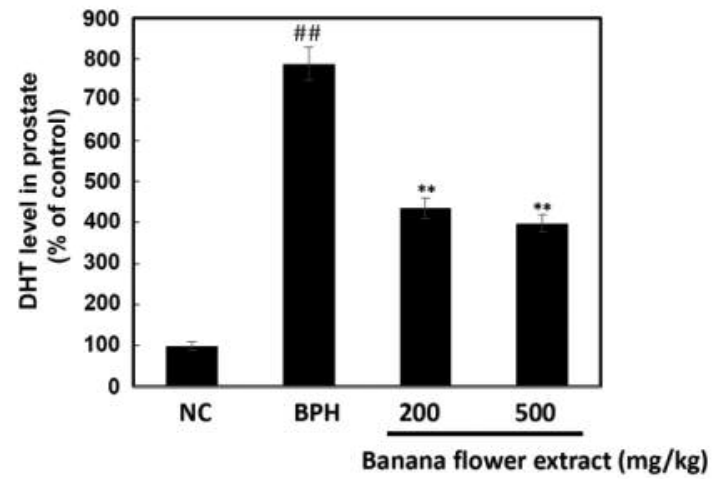

Figure 4. Effects of banana flower extract on prostate weight and serum dihydrotestosterone (DHT) concentrations in a rat model of testosterone propionate (TP)-induced BPH. A: Change in relative ratio of prostate to body weight. NC: Negative control group; BPH TP-induced control group. $B$ : Serum concentrations of DHT were measured using enzyme-linked immunosorbent assay. The data are the mean \pm SEM of three independent experiments $(n=5)$. Significantly different at ${ }^{\#} p<0.01$ compared to the NC group; ${ }^{*} p<0.05$ and ${ }^{* *} p<0.01$ compared with the BPH control group.

Moreover, treatment with banana flower extract inhibited the expression of $\mathrm{COX} 2$, an inducible enzyme that produces $\mathrm{PGE}_{2}$ during inflammation (Figure $3 \mathrm{~B}$ ). Our results suggest that banana flower extract suppresses BPH-related inflammatory responses.

Effects of banana flower extract on prostate weight and serum DHT concentrations in the TP-induced rat model of $B P H$. Prostate weight is commonly used to examine the development of $\mathrm{BPH}$. TP-induced rat model of $\mathrm{BPH}$ was used to evaluate the anti-BPH activity of banana flower extract in vivo. Our results showed that the prostate weight of rats in the TP-treated group (BPH group) significantly increased compared to the negative control group, which indicated that TP successfully induced BPH. Compared with the BPH control group, the groups treated with banana flower extract $(200 \mathrm{mg} / \mathrm{kg}$ and 500 $\mathrm{mg} / \mathrm{kg}$ ) showed a significant trend for a reduction in prostate weight (Figure 4A). We next examined whether banana flower extract attenuated the production of DHT, a product that is catalyzed through $5 \alpha \mathrm{R}$ activity. As shown in Figure 4B, a significant increase in serum DHT concentration was found in the groups treated with $\mathrm{BPH}$ compared to the NC group. In the banana flower extract-treated groups (200 and $500 \mathrm{mg} / \mathrm{kg}$ ), the serum DHT concentrations were significantly lower than for the BPH control group. In summary, our results suggest a marked recovery of prostate hyperplasia after treatment with banana flower extract.

Active compounds of banana flower extract. Active compounds of banana flower extract were analyzed quantitatively by HPLC. HPLC revealed that banana flower extract contains citric acid, taurine, pantothenic acid and nicotinic acid components.

\section{Discussion}

A range of treatment options are currently available for $\mathrm{BPH}$, including surgical interventions and medical treatment. Natural products have gained public interest in recent times due to their role in the prevention of BPH. Native communities have used banana flower as an important wild food and medicinal plant. Although recent studies have demonstrated the biological effects of banana flower, scientific study underlying banana flower action in BPH have not been carried out. To our knowledge, this is the first study to evaluate the efficacy and molecular mechanism of banana flower extract against BPH. Our study found that treatment with banana flower extract markedly inhibited BPH-1 cell proliferation through arrest at the $G_{1}$ phase. Moreover, treatment with banana flower extract significantly inhibited $\mathrm{PGE}_{2}$ production through inhibition of COX2 expression.

$\mathrm{BPH}$ is defined by hyperproliferation of stromal and epithelial cells of the prostate gland (16). Here, we showed that banana flower extract inhibited BPH-1 cell proliferation. Cell proliferation is governed by the cell cycle, which is comprised of four distinct phases: $G_{1}$ phase, Synthesis phase $(S), G_{2}$ phase and mitosis $(M)$. The transitions of $G_{1}$ to $S$ and $G_{2}$ to $M$ are regulated by various cell cycle-regulatory molecules such as CDKs, CDK inhibitors and cyclins. Banana flower extract reduced the expression of CDK6, while it increased the expression of p27. In summary, our results indicate that banana flower extract arrested cells at the $\mathrm{G}_{1}$ phase of the cell cycle.

Up-regulation of pro-inflammatory cytokines in prostate tissues of patients with BPH has been widely reported (1719). Moreover, there are many studies which have suggested that chronic prostatic inflammation may be involved in the pathogenesis of BPH (20). COX2 is an 
enzyme that has been detected in all types of inflammatory cells, and it is increased in epithelial cells from BPH samples, generating pro-inflammatory prostaglandins (21). One recent study evaluated the antioxidant potential of banana flower and the results suggested the banana flower contains potent antioxidants extractable with aqueous and organic solvents (11). In our study, treatment with banana flower extract suppressed $\mathrm{COX} 2$ expression and $\mathrm{PGE}_{2}$ production. These data suggest that the anti-BPH effects of banana flower extract might be related to its antiinflammatory activity.

In this study, the active compounds of banana flower extract were measured by HPLC. HPLC revealed that banana flower extract contains citric acid, taurine, pantothenic acid and nicotinic acid components. Recent studies reported that citric acid has various pharmacological properties, including anti-inflammatory, neuroprotective and hepatoprotective effects $(22,23)$. In addition, taurine has epithelialmesenchymal transition-inhibitory effects on human prostate cancer cells (24). Pantothenic acid may contribute to the inflammatory process through increasing CoA level and promoting glutathione synthesis, thereby reducing oxidative stress $(25,26)$. Our findings of the anti-BPH effects of banana flower extract might be related to its antiproliferative, anti-inflammatory and antioxidant activities consistent with previous studies.

\section{Conflicts of Interest}

The banana flower extract was obtained from TCI Co., Ltd., and supported partially by TCI Co., Ltd., (Taipei, Taiwan, ROC).

\section{Acknowledgements}

The efforts of Yun-Chi Wang, Huai-Mei Hsu and Hsin-Ting Li are appreciated. This study was supported partially by TCI Co., Ltd., (Taipei, Taiwan, ROC).

\section{References}

1 Allkanjari $\mathrm{O}$ and Vitalone A: What do we know about phytotherapy of benign prostatic hyperplasia? Life Sci 126: 42$56,2015$.

2 Sutton MT, Yingling M, Vyas A, Atiemo H, Borkowski A, Jacobs SC and Kyprianou N: Finasteride targets prostate vascularity by inducing apoptosis and inhibiting cell adhesion of benign and malignant prostate cells. Prostate 11: 1194-1202, 2006.

3 Penna G, Fibbi B, Amuchastegui S, Corsiero E, Laverny G, Silvestrini E, Chavalmane A, Morelli A, Sarchielli E, Vannelli GB, Gacci M, Colli E, Maggi M and Adorini L: The vitamin D receptor agonist elocalcitol inhibits IL-8-dependent benign prostatic hyperplasia stromal cell proliferation and inflammatory response by targeting the RhoA/Rho kinase and NF-kappa B pathways. Prostate 5: 480-493, 2009.
4 Girman CJ: Natural history and epidemiology of benign prostatic hyperplasia: relationship among urologic measures. Urology $4 \mathrm{~A}$ Suppl: 8-12, 1998.

5 Bushman W: Etiology, epidemiology and natural history of benign prostatic hyperplasia. Urol Clin North Am 4: 403-415, 2009.

6 Lepor H: Pathophysiology of benign prostatic hyperplasia in the aging male population. Rev Urol Suppl 4: S3-S12, 2005.

7 De Nunzio C, Presicce F and Tubaro A: Inflammatory mediators in the development and progression of benign prostatic hyperplasia. Nat Rev Urol 10: 613-626, 2016.

8 Sarbishegi M, Khani M, Salimi S, Valizadeh M and Sargolzaei Aval F: Antiproliferative and antioxidant effects of Withania coagulans extract on benign prostatic hyperplasia in rats. Nephrourol Mon 1: e33180, 2016.

9 Zhang N, Ji N, Jiang WM, Li ZY, Wang M, Wen JM, Li Y, Chen $\mathrm{X}$ and Chen JM: Hypoxia-induced autophagy promotes human prostate stromal cells survival and ER-stress. Biochem Biophys Res Commun 4: 1107-1112, 2015.

10 Chintamunnee V and Mahomoodally MF: Herbal medicine commonly used against non-communicable diseases in the tropical island of Mauritius. J Herb Med 2: 113-125, 2012.

11 Ramu R, Shirahatti PS, Anilakumar KR, Nayakavadi S, Zameer F, Dhananjaya BL and Nagendra Prasad MN: Assessment of nutritional quality and global antioxidant response of banana (Musa sp. CV. Nanjangud Rasa Bale) pseudostem and flower. Pharmacognosy Res Suppl 1: S74-S83, 2017.

12 Yu CC, Yang MD, Lin HY, Huang AC, Lin JP, Kuo CL, Liu KC, Liu HC, Yang ST and Chung JG: Bisdemethoxycurcumin (BDMC) alters gene expression-associated cell cycle, cell migration and invasion and tumor progression in human lung cancer NCI-H460 cells. In Vivo 6: 711-728, 2015.

13 Shih YL, Hung FM, Lee CH, Yeh MY, Lee MH, Lu HF, Chen YL, Liu JY and Chung JG: Fisetin induces apoptosis of HSC3 human oral cancer cells through endoplasmic reticulum stress and dysfunction of mitochondria-mediated signaling pathways. In Vivo 6: 1103-1114, 2017.

14 National Research Council (US) Committee for the Update of the Guide for the Care and Use of Laboratory Animals. Guide for the Care and Use of Laboratory Animals, 8th edition. Washington (DC): National Academies Press (US); 2011.

15 Park E, Lee MY, Jeon WY, Lee N, Seo CS and Shin HK: Inhibitory effect of yongdamsagan-tang water extract, a traditional herbal formula, on testosterone-induced benign prostatic hyperplasia in rats. Evid Based Complement Alternat Med 2016: 1428923, 2016.

16 Steers WD: 5Alpha-reductase activity in the prostate. Urology 6(Suppl 1): 17-24, 2001.

17 König JE, Senge T, Allhoff EP and König W: Analysis of the inflammatory network in benign prostate hyperplasia and prostate cancer. Prostate 2: 121-129, 2004.

18 Handisurya A, Steiner GE, Stix U, Ecker RC, PfaffenederMantai S, Langer D, Kramer G, Memaran-Dadgar N and Marberger M: Differential expression of interleukin-15, a proinflammatory cytokine and T-cell growth factor and its receptor in human prostate. Prostate 4: 251-262, 2001.

19 Giri D and Ittmann M: Interleukin-8 is a paracrine inducer of fibroblast growth factor 2, a stromal and epithelial growth factor in benign prostatic hyperplasia. Am J Pathol 1: 139-147, 2001. 
20 Robert G, Descazeaud A, Nicolaïew N, Terry S, Sirab N, Vacherot F, Maillé P, Allory Y and de la Taille A: Inflammation in benign prostatic hyperplasia: A 282 patient immunohistochemical analysis. Prostate 16: 1774-1780, 2009.

21 Ammar AE, Esmat A, Hassona MD, Tadros MG, Abdel-Naim $\mathrm{AB}$ and Guns ES: The effect of pomegranate fruit extract on testosterone-induced BPH in rats. Prostate 7: 679-692, 2015.

22 Abdel-Salam OM, Youness ER, Mohammed NA, Morsy SM, Omara EA and Sleem AA: Citric acid effects on brain and liver oxidative stress in lipopolysaccharide-treated mice. J Med Food 5: 588-598, 2014.

23 Abdel-Salam OM, Youness ER, Mohammed NA, Yassen NN, Khadrawy YA, El-Toukhy SE and Sleem AA: Novel neuroprotective and hepatoprotective effects of citric acid in acute malathion intoxication. Asian Pac J Trop Med 12: 1181-1194, 2016.
24 Tang Y, Kim YS, Choi EJ, Hwang YJ, Yun YS, Bae SM, Park PJ and Kim EK: Taurine attenuates epithelial-mesenchymal transition-related genes in human prostate cancer cells. Adv Exp Med Biol 975: 1203-1212, 2017.

25 Wojtczak L and Slyshenkov VS: Protection by pantothenic acid against apoptosis and cell damage by oxygen free radicals-the role of glutathione. Biofactors 1-4: 61-73, 2003.

26 Slyshenkov VS, Dymkowska D and Wojtczak L: Pantothenic acid and pantothenol increase biosynthesis of glutathione by boosting cell energetics. FEBS Lett 1-3: 169-172, 2004.

Received July 31, 2018

Revised September 19, 2018

Accepted September 25, 2018 